\title{
Rectosigmoidian Involvement in Advanced-stage Ovarian Cancer - Intraoperative Decisions
}

\author{
NICOLAE BACALBASA ${ }^{1}$, IRINA BALESCU ${ }^{2}$ and SIMONA DIMA ${ }^{3}$ \\ ${ }^{1}$ Department of Obstetrics and Gynecology, Carol Davila University of Medicine and Pharmacy, Bucharest, Romania; \\ ${ }^{2}$ Department of General Surgery, Ponderas Academic Hospital, Bucharest, Romania; \\ ${ }^{3}$ Department of General Surgery, "Dan Setlacec” Center of Gastrointestinal Disease and Liver Transplantation, \\ Fundeni Clinical Institute, Bucharest, Romania
}

\begin{abstract}
Background/Aim: Ovarian cancer remains one of the most commonly encountered malignancies affecting women worldwide, that is unfortunately commonly diagnosed in advanced stages of the disease. In these stages, the tumoral process usually involves the surrounding viscera throughout contiguity or induces the apparition of distant metastases via peritoneal, lymphatic or hematogenous spread, multiple resections being needed in order to achieve a good control of the disease. Patients and Methods: In the present study, we present a case series of 12 patients in whom various surgical procedures on the rectosigmoidian loop were performed in order to achieve debulking surgery to no residual disease. Results: Digestive tract resections consisted of rectosigmoidian resection with left colostomy in three cases, low rectosigmoidian resections with anastomosis in eight cases and a stripping procedure of the peritoneal layer in one case. Conclusion: Due to the close proximity of the digestive and gynecological tract, advancedstage ovarian tumors frequently involve the rectosigmoidian loop, imposing association of digestive tract surgical procedures.

Ovarian cancer is a common malignancy encountered in women worldwide, presenting an increasing incidence in the last decades. Among European women it is estimated that the incidence of ovarian cancer reached $4 \%$ of all malignancies, being in the meantime the sixth cause of cancer related death $(1,2)$. This fact is mainly related to the high capacity of spread of the malignant process via multiple pathways,
\end{abstract}

This article is freely accessible online.

Correspondence to: Irina Balescu, Department of General Surgery, Ponderas Academic Hospital, Bucharest, Romania. Tel: +40 724077709, e-mail: irina.balescu@ ponderas-ah.ro

Key Words: Advanced stage ovarian cancer, rectosigmoidian loop, resection, peritonectomy. leading to the apparition of disseminated lesions at the time of diagnosis. In these cases, despite advances in chemotherapy, the five-year survival rate remains low, the most significant prognostic factor remaining the stage of disease at diagnosis and the completion of cytoreductive surgery (3-10). Intuited for the first time by Meigs (4) in 1934 and demonstrated four decades later by Griffiths (5), the principles of debulking surgery became the standard of care whenever disseminated lesions are encountered. When it comes to the presence of disseminated lesions involving the lower digestive tract, multiple surgical procedures might be taken in consideration in order to maximize the debulking effort as well as the functional outcome and, in the meantime to minimize the risk of postoperative complications (11-14).

\section{Patients and Methods}

We present a case series of 12 patients diagnosed with advanced stage ovarian cancer with rectosigmoidian involvement submitted to surgery between 2014 and 2016. In all cases at least one digestive tract resection was performed. At the end of each surgical procedure, two drainage tubes were placed in the pelvic area in all cases while the decompression naso-gastric tube was left in place until the intestinal transit was re-established.

\section{Results}

The mean age at diagnosis was 56.5 years (range=33-78 years). Preoperative status was assessed based on ASA score, eight patients being classified as having ASA score I-II while the other four patients were classified as having ASA score III. The main associated comorbidities included cachexia in two cases, morbid obesity in three cases, diabetes mellitus in two cases and cardiovascular disease in one case. Both patients presenting cachexia were diagnosed with low preoperative levels of albumin, prealbumin and total proteins. In all cases the surgical procedure consisted of total hysterectomy with bilateral adnexectomy, pelvic and para-aortic lymph node 


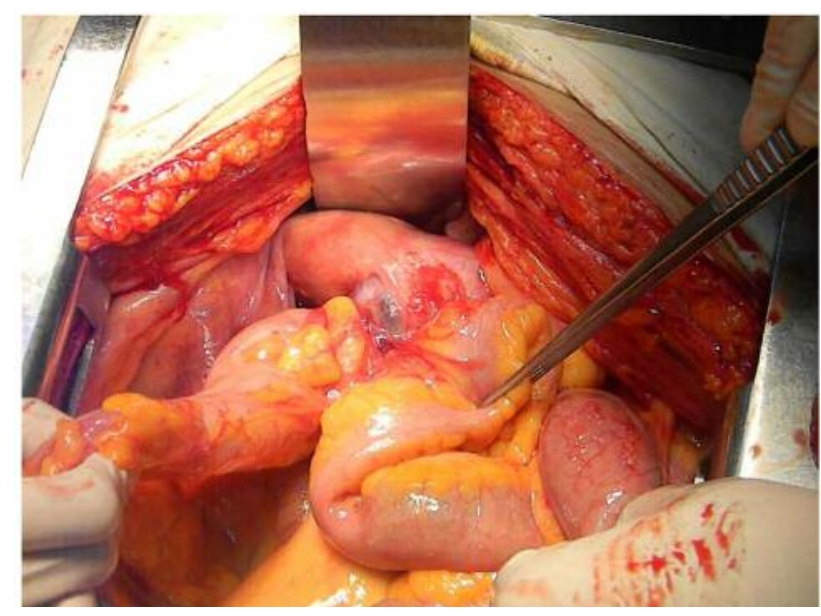

Figure 1. Large ovarian tumor invading the rectosigmoid and an ileal loop.

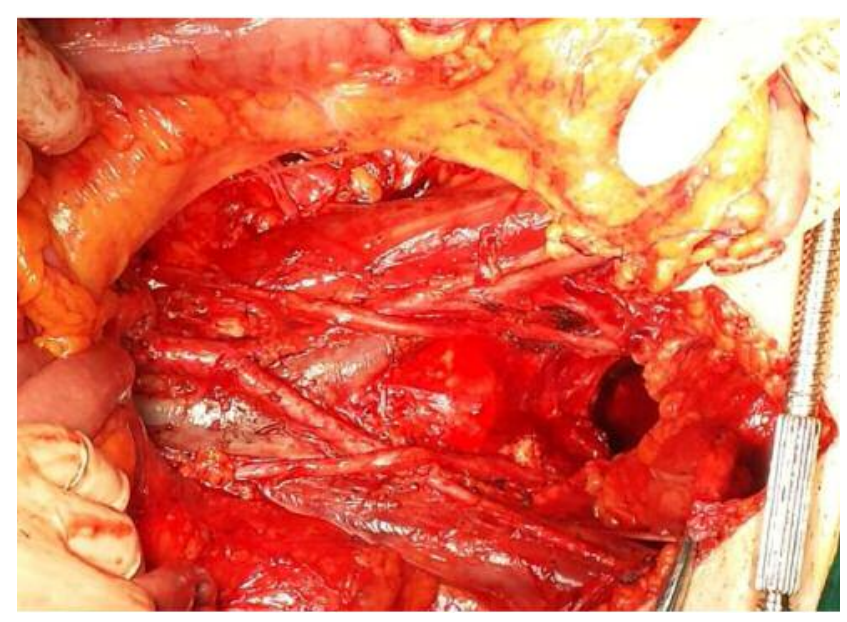

Figure 2. The final aspect after total hysterectomy, bilateral adnexectomy and Hartmann procedure.

The decision of performing only peritoneal stripping of the Douglas pouch was taken in a patient diagnosed with stage IIIC ovarian cancer with disseminated peritoneal lesions at this level, but with no evidence of deep invasion of the rectosigmoidian layer. The same surgical procedure was also performed at the level of the anterior surface of the rectosigmoid colon and on the peritoneal surface of the urinary bladder where disseminated small nodules were also encountered. In this case, although the rectosigmidian loop was entirely preserved, the resection of an ileal loop was imposed by the presence of the disseminated tumoral lesions on the mesenteric surface.

\section{Discussion}

Once the principle of debulking surgery to no residual disease became the golden standard in advanced stage and relapsed ovarian cancer, the situation in which multiple visceral resections were performed in order to achieve this golden standard became a common one. In the last decade improvement of the surgical technique of both pelvic and upper abdominal surgical procedures including hepatobilio-pancreatic procedures encouraged the oncosurgical teams to include these types of procedures in the armamentarium of debulking surgery with good short-term and long-term results, maximizing in this way the cytoreductive effort (14-20).

When it comes to the necessity of bowel resection as part of the debulking surgery for advanced-stage ovarian cancer, the type of surgical procedure which is performed should take into consideration multiple factors such as the depth of invasion of the peritoneal nodules, the patient's nutritional and biological status as well as the extent of the lesions. In 


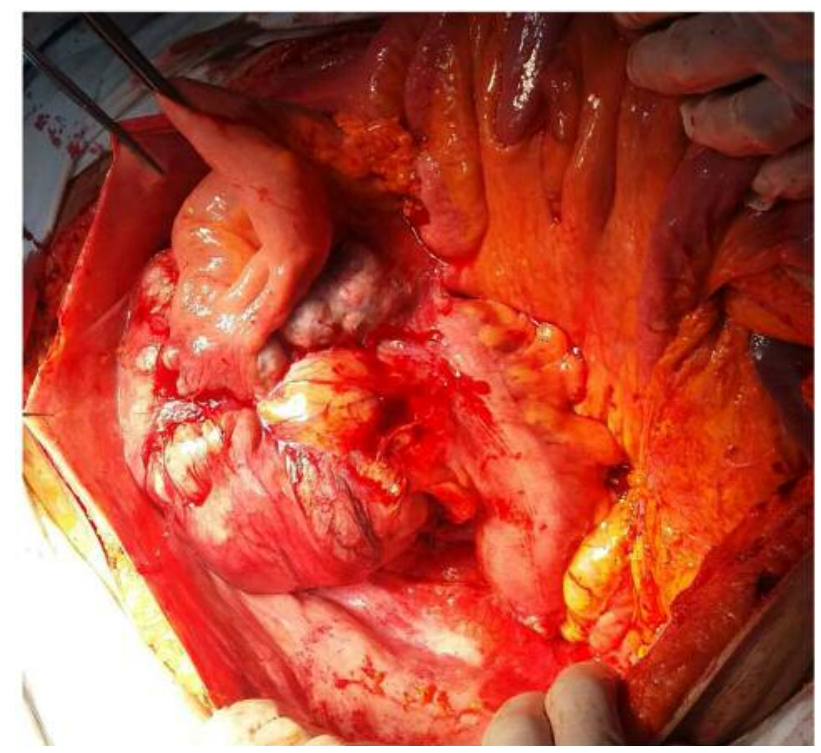

Figure 3. Large ovarian tumor with rectosigmoidian and ileal invasion.

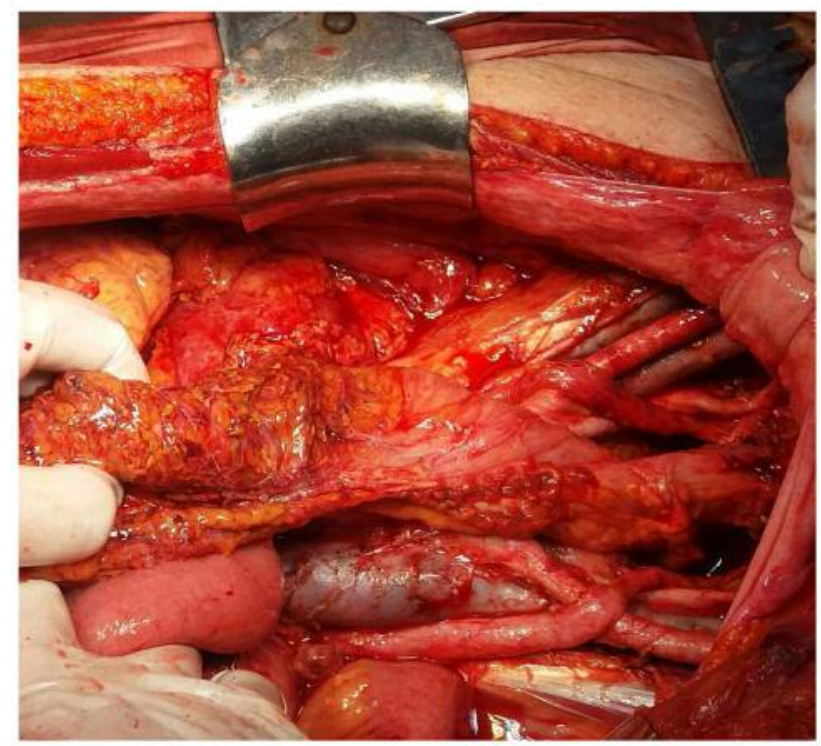

Figure 4. The final aspect after total hysterectomy with bilateral adnexectomy, pelvic and para-aortic lymph node dissection, low rectosigmoidian resection with colorectal anastomosis.

most cases the decision of what procedure is the most suitable for each patient is taken intraoperatively, after a close inspection of the local situation and after the integration of these aspects in the general status of each case. Whenever the surgical team decides to perform a low rectosigmoidian

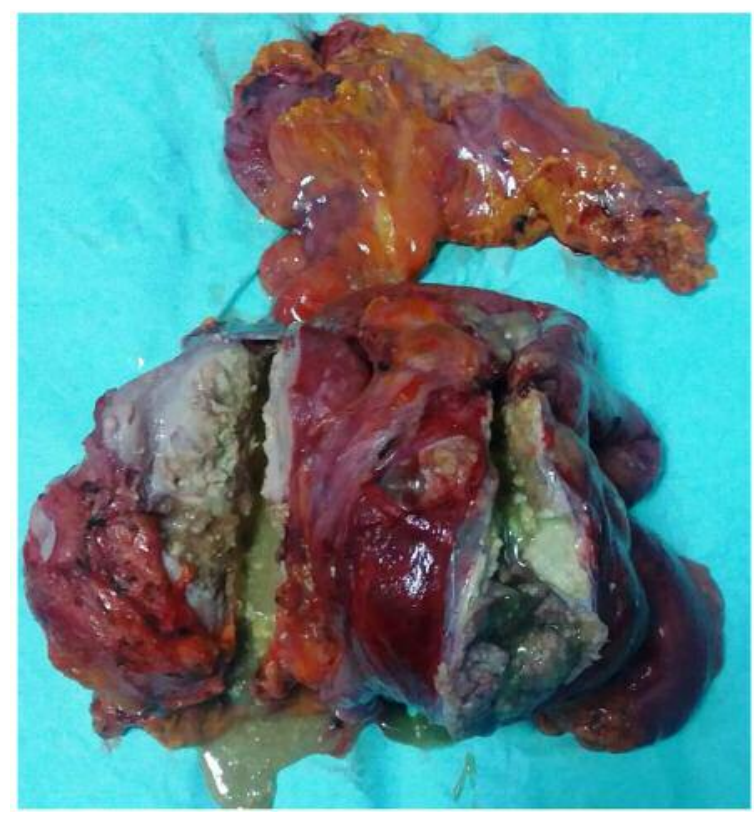

Figure 5. The specimen: large necrotized abscessed tumor with rectosigmoidian and ileal resection.

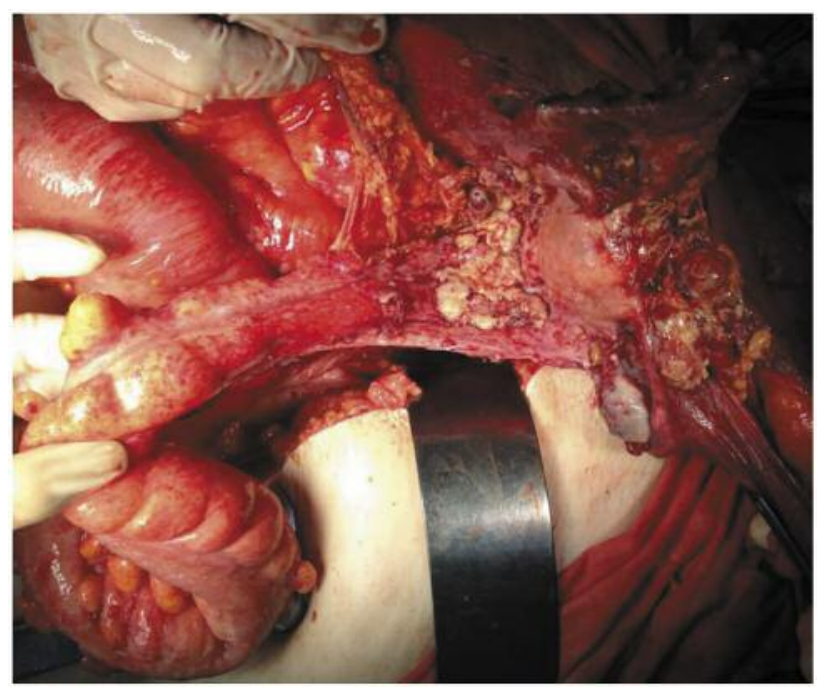

Figure 6. Disseminated peritoneal nodules of the Douglas cul de sac.

resection with anastomosis, the surgeon should take into consideration the fact that in this context the risk of anastomotic dehiscence remains one of the most frequent and serious complications, ranging between 0.8 and $6.8 \%$ (21, 22 ). In the meantime, the factors contributing to a higher risk 


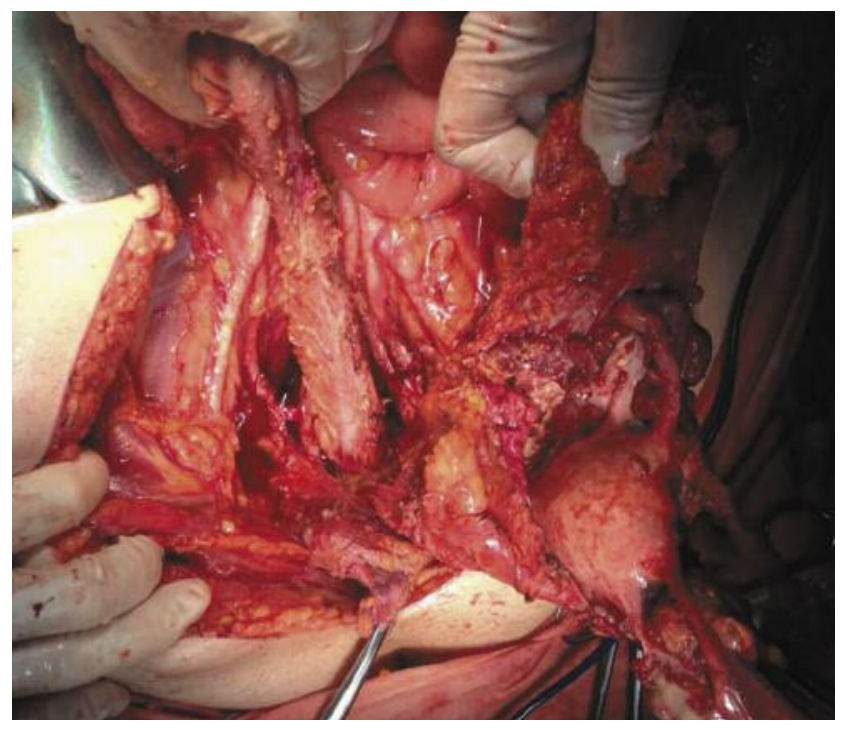

Figure 7. Performing pelvic peritoenctomy of the Douglas Pouch.

of anastomotic leaks consist of a higher length of operative time, a higher need of blood transfusion and a shorter length of the distal anastomotic partner (2). Whenever one of these situations are encountered, performing a diverting ileostomy or even a Hartmann procedure might be performed in order to minimize the risk of a life-threatening complication such as an anastomotic leak.

In order to determine the impact of rectosigmoidian resection as part of debulking surgery for advanced-stage ovarian cancer, Kalogera et al. conducted a study on 42 patients submitted to multiple bowel resections for advanced stage ovarian cancer who experienced postoperative anastomotic leaks, these results being compared to a similar group of 84 controls - patients with similar preoperative characteristics submitted to debulking surgery which included bowel resections but who did not experience any anastomotic leak. The author demonstrated that the addition of another large bowel resection to rectosigmoidian resection associated with a significantly higher risk of anastomotic leak $(p=0.025)$ while the decision of performing a protective ileostomy significantly decreased the risk of anastomotic leak $(p=0.024)$. In the same study, other factors such as BMI value, ASA score, diabetes mellitus or smoking did not significantly influence the apparition of anastomotic leaks (23).

When it comes to the decision of performing a Douglas peritonectomy or rectosigmoidian resection with anastomosis, one of the most important factors which will influence the therapeutic strategy is related to the depth of invasion of the peritoneal nodules. Although peritonectomy of the Douglas cul de sac with rectosigmoidian preservation is usually the procedure of choice, the local involvement might impose

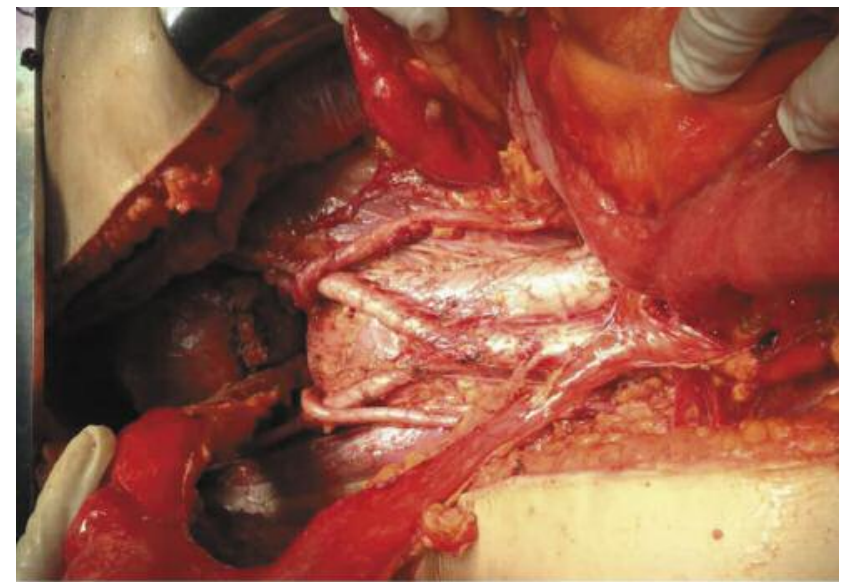

Figure 8. The final aspect after total hysterectomy with bilateral adnexectomy, pelvic and para-aortic lymph node dissection and Douglas peritonectomy.

performing a more radical surgical procedure such as rectosigmoidian resection. However, if complete cytoreduction is achieved it seems that similar rates of survival are expected, independently of the procedure of choice. One of the largest studies conducted on this theme comes from Gallotta et al. and was published in 2011 in the European Journal of Surgical Oncology. In this study, the authors included 187 patients with advanced stage ovarian cancer who were submitted to pelvic peritonectomy of Douglas pouch (116 cases) and to rectosigmoidian resections (in 71 cases). The authors reported similar rates of disease free and overall survival between the two groups, demonstrating the efficacy of the two procedures as long as the desideratum of complete debulking surgery is achieved (24). The same study also demonstrated that the rate of pelvic recurrence was significantly higher among patients submitted to peritonectomy when compared to those submitted to per primam rectosigmoidian resection. However, this fact did not significantly influence survival due to the fact that whenever pelvic recurrence was suspected the patient was submitted to secondary cytoreductive surgery (24). These data are only partially in agrrement with those reported by Alletti et al. who demonstrated that performing a peritoneal stripping of the Douglas pouch is associated with higher rates of recurrence and significantly lower rates of a five-year overall survival when compared to rectosigmoidian resection. Alletti explained the poorer outcome of cases submitted to pelvic peritonectomy when compared to those submitted to rectosigmoidian resection through the fact that the exact extent of the disease in the depth of the rectal wall can be easily underestimated; in this situation, performing a peritonectomy might leave in place a high amount of tumor cells in the inner layers of the rectosigmoidian loop, predisposing both to a higher recurrence rate and a lower rate of long-term survival (14). 


\section{Conclusion}

Due to the close proximity of the gynecological and the digestive tract, rectosigmoidian involvement can be frequently encountered in cases presenting advanced-stage ovarian malignancies. The presence of extended pelvic lesions should not preclude obtaining a complete macroscopic resection of the tumoral burden and to increase the rate of long-term survival. However, the type of surgical procedure should be carefully chosen, after a close inspection of the local degree of invasion of the lesions and after integrating this information with the general and biological status of the patient.

\section{References}

1 De Angelis R, Sant M, Coleman MP, Francisci S, Baili P, Pierannunzio D, Trama A, Visser O, Brenner $\mathrm{H}$, Ardanaz E, Bielska-Lasota M, Engholm G, Nennecke A, Siesling S, Berrino F and Capocaccia R: Cancer survival in Europe 1999-2007 by country and age: results of EUROCARE--5-a population-based study. Lancet Oncol 15: 23-34, 2014

2 Derlatka P, Sienko J, Grabowska-Derlatka L, Palczewski P, Danska-Bidzinska A, Bidzinski M and Czajkowski K: Results of optimal debulking surgery with bowel resection in patients with advanced ovarian cancer. World J Surg Oncol 14: 58, 2016.

3 Nakayama K, Nakayama N, Katagiri H and Miyazaki K: Mechanisms of ovarian cancer metastasis: biochemical pathways. Int J Mol Sci 13: 11705-11717, 2012.

4 JV Meigs: Tumors of the female pelvic organs. New York, Macmillan, 1934

5 Griffiths CT: Surgical resection of tumor bulk in the primary treatment of ovarian carcinoma. Natl Cancer Inst Monogr 42: 101-104, 1975.

6 Bacalbasa N, Balescu I, Dima S and Popescu I: Long-term Survivors After Liver Resection for Ovarian Cancer Liver Metastases. Anticancer Res 35: 6919-6923, 2015.

7 Bristow RE, Tomacruz RS, Armstrong DK, Trimble EL and Montz FJ: Survival effect of maximal cytoreductive surgery for advanced ovarian carcinoma during the platinum era: a metaanalysis. J Clin Oncol 20: 1248-1259, 2002.

8 Bacalbasa N, Balescu I, Dima S, Herlea V, David L, Brasoveanu $\mathrm{V}$ and Popescu I: Initial incomplete surgery modifies prognosis in advanced ovarian cancer regardless of subsequent management. Anticancer Res 35: 2315-2320, 2015.

9 Bacalbasa N, Dima S, Balescu I, David L, Brasoveanu V and Popescu I: Results of Primary Cytoreductive Surgery in Advanced-stage Epithelial Ovarian Cancer: A Single-center Experience. Anticancer Res 35: 4099-4104, 2015.

10 Eisenkop SM, Nalick RH and Teng NN: Modified posterior exenteration for ovarian cancer. Obstet Gynecol 78: 879-885, 1991.

11 Gillette-Cloven N, Burger RA, Monk BJ, McMeekin DS, Vasilev S, DiSaia PJ and Kohler MF: Bowel resection at the time of primary cytoreduction for epithelial ovarian cancer. J Am Coll Surg 193: 626-632, 2001.

12 Hoffman MS, Griffin D, Tebes S, Cardosi RJ, Martino MA, Fiorica JV, Lockhart JL and Grendys EC Jr.: Sites of bowel resected to achieve optimal ovarian cancer cytoreduction: implications regarding surgical management. Am J Obstet Gynecol 193: 582-586, 2005.

13 Kim HS, Kim EN, Jeong SY, Chung HH, Kim YB, Kim JW, Park KJ, Park NH, Song YS, Park JG and Kang SB: Comparison of the efficacy of low anterior resection with primary anastomosis and Hartmann's procedure in advanced primary or recurrent epithelial ovarian cancer. Eur J Obstet Gynecol Reprod Biol 156: 194-198, 2011.

14 Aletti GD, Podratz KC, Jones MB and Cliby WA: Role of rectosigmoidectomy and stripping of pelvic peritoneum in outcomes of patients with advanced ovarian cancer. J Am Coll Surg 203: 521-526, 2006.

15 Chang SJ and Bristow RE: Evolution of surgical treatment paradigms for advanced-stage ovarian cancer: redefining 'optimal' residual disease. Gynecol Oncol 125: 483-492, 2012.

16 Salani R, Zahurak ML, Santillan A, Giuntoli RL and Bristow RE: Survival impact of multiple bowel resections in patients undergoing primary cytoreductive surgery for advanced ovarian cancer: a case-control study. Gynecol Oncol 107: 495-499, 2007.

17 Bacalbasa N, Balescu I, Dima S, Brasoveanu V and Popescu I: Pancreatic Resection as Part of Cytoreductive Surgery in Advanced-stage and Recurrent Epithelial Ovarian Cancer--A Single-center Experience. Anticancer Res 35: 4125-4129, 2015.

18 Bacalbasa N, Dima S, Brasoveanu V, David L, Balescu I, Purnichescu-Purtan R and Popescu I: Liver resection for ovarian cancer liver metastases as part of cytoreductive surgery is safe and may bring survival benefit. World J Surg Oncol 13: 235, 2015.

19 Bacalbasa N, Balescu I, Dima S, Brasoveanu V and Popescu I: Splenectomy as Part of Cytoreductive Surgery in Recurrent Epithelial Ovarian Cancer. Anticancer Res 35: 5097-5101, 2015.

20 Bacalbasa N, Balescu I, Dima S, Brasoveanu V and Popescu I: Hematogenous Splenic Metastases as an Independent Negative Prognosis Factor at the Moment of Primary Cytoreduction in Advanced Stage Epithelial Ovarian Cancer - A Single Center Experience. Anticancer Res 35: 5649-5654, 2015.

21 Bristow RE, del Carmen MG, Kaufman HS and Montz FJ: Radical oophorectomy with primary stapled colorectal anastomosis for resection of locally advanced epithelial ovarian cancer. J Am Coll Surg 197: 565-574, 2003.

22 Obermair A, Hagenauer S, Tamandl D, Clayton RD, Nicklin JL, Perrin LC, Ward BG and Crandon AJ: Safety and efficacy of low anterior en bloc resection as part of cytoreductive surgery for patients with ovarian cancer. Gynecol Oncol 83: 115-120, 2001.

23 Kalogera E, Dowdy SC, Mariani A, Weaver AL, Aletti G, Bakkum-Gamez JN and Cliby WA: Multiple large bowel resections: potential risk factor for anastomotic leak. Gynecol Oncol 130: 213-218, 2013.

24 Gallotta V, Fanfani F, Vizzielli G, Panico G, Rossitto C, Gagliardi ML, Margariti PA, Salerno MG, Zannoni GF, Pacelli F, Scambia G and Fagotti A: Douglas peritonectomy compared to recto-sigmoid resection in optimally cytoreduced advanced ovarian cancer patients: analysis of morbidity and oncological outcome. Eur J Surg Oncol 37: 1085-1092, 2011.

Received June 4, 2017

Revised July 2, 2017

Accepted July 4, 2017 